\title{
All-Purpose Nanostrategy Based on Dose Deposition Enhancement, Cell Cycle Arrest, DNA Damage and ROS Production as Prostate Cancer Radiosensitizer for Potential Clinical Translation
}

\author{
Xiao-xiao Guo \\ Beijing Hospital \\ Zhen-hu Guo \\ Tsinghua University \\ Meng Wu \\ Beijing Hospital \\ Jing-song Lu \\ Tsinghua University \\ Wen-sheng Xie \\ Tsinghua University \\ Qiu-zi Zhong \\ Beijing Hospital \\ Yong-jie Chi \\ Tsinghua University \\ Xiao-dan Sun \\ Tsinghua University \\ Xiu-mei Wang \\ Tsinghua University \\ Jian-ye Wang \\ Beijing Hospital \\ Ming Liu \\ Beijing Hospital
}

Lingyun Zhao ( $\square$ lyzhao@mail.tsinghua.edu.cn )

Tsinghua University https://orcid.org/0000-0001-7999-9707

\section{Research}

Keywords: prostate cancer, radiotherapy, G2/M phases arrest, Au nanospheres, All-purpose radiosensitization 
Posted Date: June 15th, 2021

DOl: https://doi.org/10.21203/rs.3.rs-608913/v1

License: (c) (i) This work is licensed under a Creative Commons Attribution 4.0 International License. Read Full License 


\section{Abstract \\ Background}

Radiotherapy (RT) is one of the main treatments for men with prostate cancer (PCa). Yet, to date, with numerous sophisticated nano-formulations as radiosensitizers have been synthesized with inspiring therapeutic effect both in vitro and in vivo, there still lacks the successful clinical translation of such nanosystems. Meanwhile, almost all the attention has been paid on the enhanced dose deposition effect by secondary electrons of nanomaterials with high atomic numbers (Z), despite that cell-cycle arrest, DNA damage and also reactive oxygen species (ROS) production are critical working mechanisms accounting for radiosensitization.

\section{Methods}

Herein, an 'all-purpose' nanostrategy based on dose deposition enhancement, cell cycle arrest and ROS production as prostate cancer radiosensitizer for potential clinical translation was proposed. The rather simple structure of docetaxel loaded Au nanoparticles (NPs) with prostate specific membrane antigen (PSMA) ligand conjugation have been successfully synthesized by a rather facile protocol.

\section{Results}

Enhanced cellular uptake achieved via selective internalization of the NPs by PCa cells with positive PSMA expression could guarantee the enhanced dose deposition. Moreover, the as-synthesized nanosystem could arrest cell cycle at G2/M phases, which would reduce the ability of DNA damage repair for more irradiation sensitive of the PCa cells. Meanwhile, G2/M phases arrest would further promote cascade retention and enrichment of the NPs within the cells. Furthermore, ROS generation and double strand breaks greatly promoted by the NPs under irradiation (IR) could also provide an underlying basis for effective radiosensitizers.

\section{Conclusions}

Investigations from in vitro and in vivo confirmed the as-synthesized NPs as an effective nanoradiosensitizer with ideal safety. More importantly, all the moieties within the present nanosystem have been approved by FDA for the purpose of PCa treatment, thus making the it highly attractive for clinical translation.

\section{Background}

Prostate cancer ( $\mathrm{PCa})$, the second most frequent cancer among male patients, has estimated 1.1 million new cases with $15 \%$ of all diagnosed cancers worldwide every year.[1] Till now, radical prostatectomy is 
regarded as the gold standard clinical treatment for localized PCa, but surgery could nevertheless destruct urethral sphincter and pelvic floor structure potentially, which would lead to incontinence and erectile disfunction.[2,3] In addition, patients with severe complications or older individuals usually are intolerant to radical surgery. As a non-invasive treatment, radiotherapy (RT) serves as the major surrogate for frail patients or those who take life quality seriously. The anti-tumor efficiency of RT, however, is inferior to that of radical prostatectomy.[4] Moreover, high dose RT has complications itself, such as blood in urine, rectal leaking, and even secondary cancer.[5] Our previous study has reported that RT for PCa can even increase the incidence of secondary bladder cancer.[6] Therefore, it would be of great significance to develop new strategies to improve the oncological outcomes of RT, ensuring the therapeutic efficiency while reducing the radiation dose so as to avoid unnecessary exposure of normal tissues for potential radiotoxicity.

Enhanced therapeutic efficacy of RT can be achieved by introducing high atomic number (Z) nanoparticles as radiosensitizer as they can enhance photoelectric interactions and Auger effects, thereby increasing energy deposition in tumors and improving RT outcomes[7, 8]. However, with numerous researches on design and synthesis of various novel nano-formulations as radiosensitizers which showing inspiring therapeutic effect both in vitro and in vivo, there still lacks the successful benchto-bed translation of such nanosystems. The successful clinical translation of nano-formulations in the chemotherapy, thermotherapy and imaging may shed some lights on the design and translational research of nano-agents as radiosensitizer. In principle, the fabrication of nano-formulations under clinical trials are normally based on a quite conventional protocol with controllable size/morphology and rather simple structure. Too sophisticated synthesis steps and complicated structure may encounter more challenging before adoption in clinical practice due to safety concern for patients. Secondly, the rational utilization of unique features and advantages of approved formulations may also set the basis of successful clinical translation. For instance, doxorubicin known as chemotherapeutic agent widely applied in clinical, also displays remarkable immunomodulatory properties.[9] Currently, about 20 clinical trials on nano-immunotherapy based on doxorubicin combined with PD-1/L1 checkpoint blockers are being conducted with the most advanced stage study of the phase III JAVELIN 200 trial.[10] Such attempts of repurposing clinical first line medicines for new applications also bring some new ideas for design and research of nano-radiosensitizer to facilitate the clinical translation.

Except for enhanced dose deposition effect by secondary electrons, the mechanism of action of radiosensitizers currently applied in clinical also include cell-cycle arrest, DNA damage and also reactive oxygen species (ROS) production, etc.[11] However, with special attention paid on enhanced dose deposition by high-Z nanomaterials, the other mechanisms are normally neglected when designing the nano-radiosensitizer. Herein, with the attempt to develop an all-propose and effective nanosystem as radiosensitizer potentially for clinical translation, docetaxel (DTX) loaded Au NPs with 2-[3-(1,3Dicarboxypropyl) ureido] pentanedioic acid (DUPA) coating was proposed and successfully fabricated by a facile protocol. DTX has been approved by FDA as first-line chemotherapeutic agent for PCa with the working mechanism mainly involving microtubular depolymerization inhibition to arrest cells in $\mathrm{G} 2 / \mathrm{M}$ phases.[12] Apart from the pharmacology, DTX has also been widely reported as an effective 
radiosensitization agent.[13] With up to a 100-fold enhancement in the keV energy range, gold has a much higher absorbance of radiation compared to normal tissue and the effectiveness of Au NPs as radiosensitizer has been confirmed.[14] More importantly, a clinical pilot trial using Au NPs as agent for photothermal ablation in patients with low- to intermediate- risk PCa has demonstrated safety of Au NPs. [15] DUPA, one of the highest-affinity small molecular ligands of prostate specific antigen (PSMA), had been used for clinical trial for targeting radioimaging.[16] It was worth noting that all the three moieties within the nanosystem have been approved by FDA for the purpose of PCa treatment. However, no attempt has been performed to combine them into one nano-platform as all-purpose radiosensitizer for PCa treatment, i.e. radiosensitization based on enhanced dose deposition effect, cell-cycle arrest, DNA damage as well as ROS production could be achieved. A detailed design and therapeutic strategy of DTX loaded Au NPs with DUPA coating (Au@DTX-DUPA) is presented in Scheme 1. The safety and effectiveness of the synthesized NPs as radiosensitizer were systematically tested. More importantly, the effect of the nanosystem on cell cycle redistribution, ROS production and also DNA damage was systematically investigated. All the observations of the nanosystem in the PCa accurate RT treatment make it an all-purpose nano-radiosensitizer potentially for clinical PCa treatment.

\section{Methods Or Experimental Section}

\section{Materials}

Chloroauric acid, tetrahydrate $\left(\mathrm{HAuCl}_{4} \cdot 4 \mathrm{H}_{2} \mathrm{O}, 99 \%\right)$, 1-ethyl-3-(3-dimethylaminopropyl) carbodiimide (EDC) was purchased from Sinopharm Chemical Reagent Co., Ltd. (Shanghai, China). DTX and PSMA antibody were purchased from Sigma-Aldrich (St. Louis, USA). DUPA (OtBu)-OH was purchased from Med Chem Express (New Jersey, USA). Cell Counting Kit-8 (CCK-8) was purchased from Dojindo Molecular Technologies (Japan). Deionized water with resistivity of $18.2 \mathrm{M} \Omega \cdot \mathrm{cm}$ was used in all of the experiments. All agents were used without further purification.

\section{Synthesis of Au@DTX-DUPA NPs}

Au NPs were prepared by the typical reduction method[17] (Supporting information). For Pegylated Au NPs, excess of $\mathrm{SH}-\mathrm{PEG}_{2 \mathrm{~K}}-\mathrm{NH} 2$ and $\mathrm{SH}-\mathrm{mPEG}_{2 \mathrm{~K}}$ ligands in ratio of 1:4 molar was used to react with 1 equiv of naked Au NPs for $12 \mathrm{~h}$. To visualize the PEG corona, the PEGylated Au NPs samples were stained with $2 \%$ phosphotungstic acid prior to TEM observation. Pegylated Au-DUPA NPs was synthesized as previously reported with minor modifications. $[18,19]$ Briefly, DUPA(OtBu)-OH $(0.2 \mathrm{mmol})$ was dissolved in dichloromethane $(10 \mathrm{~mL})$, followed by the addition of Hydroxybenzotriazole (1 equiv), EDC- $\mathrm{HCl}$ (2 equiv), and triethylamine (1 equiv), in ice bath for $1 \mathrm{~h}$. Subsequently, Pegylated Au NPs modified with amino terminal PEG $(0.01 \mathrm{~g})$ dispersed in dichloromethane $(5 \mathrm{ml})$ were added to mixed system, the reaction mixture was stirred at room temperature for $24 \mathrm{~h}$ in a $\mathrm{N}_{2}$ atmosphere. Then, the protected group of DUPA(OtBu)-OH were removed by the addition of trifluoroacetic acid (TFA, 50\%). Next, the organic solvent was removed by reduced pressure distillation to yield Au-DUPA NPs. Excess ligands 
and other reaction products were removed by extensive purification ( $\mathrm{MWCO}=30 \mathrm{kDa}$ ) for 3 times. The purified Au-DUPA NPs were collected and followed by freeze-drying.

\section{DTX Loading and Release}

DTX was encapsulated into PEGylated Au-DUPA NPs through the non-covalent interaction to construct the Au@DTX-DUPA NPs. First, DTX was added to Au-DUPA NPs in dichlormethane solution with gradient weight ratio (DTX/Au-DUPA NPs $=1: 50,1: 25,3: 50,1: 12.5,1: 10,1: 8.3,1: 7.1,1: 6.25)$. Then, the mixture was slowly stirred at room temperature for four days. After dichlormethane was completely evaporated, the products were re-dispersed into $10 \mathrm{~mL}$ DI water for further UV-Vis analysis. The typical band of free DTX in water was set as reference. The disappearance of the typical band of DTX indicated that there was no free DTX in the supernatant and almost all DTX molecules were encapsulated into the PEG coronal of Au-DUPA NPs. In order to evaluate in vitro DTX release from Au@DTX-DUPA NPs, HBSS was chosen as simulated body fluid. In brief, 2.0 mg of Au@DTX-DUPA NPs was loaded into a dialysis tubing (retention molecular weight $12 \mathrm{kD}$ ) and then the dialysis tubing was maintained in $40 \mathrm{~mL}$ HBSS in a $37^{\circ} \mathrm{C}$ water bath shaker. At designed time interval, $0.5 \mathrm{~mL}$ HBSS was obtained for DTX detection and another $0.5 \mathrm{~mL}$ fresh HBSS was supplemented. For DTX detection, the obtained releasing mixture were extracted with dichloromethane twice. Then $0.5 \mathrm{~mL}$ methanol was added to dissolve DTX for further highperformance liquid chromatography assay. The mobile phase was acetylene and the chromatography column was Agilent ZORBAX Eclipse XDB-C18 (5 $\mu \mathrm{m})$.

\section{Cell Culture and In Vitro Cytotoxicity}

Human PCa cell lines (PC-3, 22RV1) and mouse fibroblast cell line (L929) were purchased from Cell Bank of Type Culture Collection of Chinese Academy of Sciences and maintained in RPMI-1640 medium supplemented with $10 \%$ Fetal Bovine Serum, $50 \mu \mathrm{g} / \mathrm{mL}$ penicillin, $50 \mu \mathrm{g} / \mathrm{mL}$ streptomycin, and $2 \mathrm{mM} \mathrm{L-}$ glutamine. The biocompatibility of Au-DUPA NPs was evaluated with L929 cell line. L929 cells were seeded in 96-well plate and grown for $24 \mathrm{~h}$. Then, cells were incubated with cell culture medium containing different concentrations of Au-DUPA NPs for 24 and $48 \mathrm{~h}$, respectively. Next, the cells survival was calculated by CCK-8 assay. To compare the cytotoxicity of Au@DTX-DUPA NPs and free DTX and identified EC50 values of two agents for 22RV1 cell. 22RV1 cells were seeded in 96-well plate and grown for $24 \mathrm{~h}$. Then, cells were incubated with cell culture medium containing different concentrations of Au@DTX-DUPA NPs and free DTX for $24 \mathrm{~h}$. Next, the cells viability was determined by CCK-8 assay. The dose-effect curves of Au@DTX-DUPA NPs and free DTX were built and the EC50 of two agents for 22RV1 cells were identified, Absorbance was measured at $450 \mathrm{~nm}$ using 96-well plate reader (Varioskan Flash, Thermo).

\section{Cellular Uptake of Au-DUPA NPs}

First, the expression of PSMA on 22RV1 and PC3 cell lines were determined by immunohistochemistry. Then, two kinds of cells were incubated with $30 \mu \mathrm{g} / \mathrm{mL}$ FITC-labeled Au-DUPA NPs for $24 \mathrm{~h}$ in 6-well plates. Then, the cells were washed with HBSS $(\mathrm{pH}=7.4)$ twice and stained with Hoechst $33342(2$ 
$\mu \mathrm{g} / \mathrm{mL}$ ) for 10 min at $37^{\circ} \mathrm{C}$. Afterward, the cells were washed with HBSS again, and observed by confocal laser scanning microscope. All images were collected on a Nikon laser scanning confocal microscope system with a 20X objective. The FITC-labeled NPs were detected by an excitation wavelength of $488 \mathrm{~nm}$ and an emission wavelength of $535 \mathrm{~nm}$. Hoechst 33342 was activated by an excitation wavelength of $343 \mathrm{~nm}$ and an emission wavelength of $483 \mathrm{~nm}$ to label nucleus. The intracellular content of Au was quantified by ICP-MS (NexION 300 D, PerkinElmer Corporation, USA).

\section{Detection and Quantification of Cell Cycle and Intracellular NPs Concentration}

The effects of various treatments on the cell cycle distribution were analyzed by FACS (BD FACSARIA, Bio-Rad). The 22RV1 cells were incubated with Au-DUPA NPs, free DTX, or Au@DTX-DUPA NPs. After indicated incubated periods $(8,16,24 \mathrm{~h})$, the medium was removed, and 22RV1 cells were harvested by trypsinization, centrifugation, and fixed in $70 \%$ ice-cold ethanol at $4{ }^{\circ} \mathrm{C}$ overnight. Afterward, the cells were washed, re-suspended and treated with $10 \mu \mathrm{g} / \mathrm{mL}$ RNase (Sigma-Aldrich Co., US) for $30 \mathrm{~min}$ at 37 ${ }^{\circ} \mathrm{C}$, and then stained with HBSS containing $50 \mu \mathrm{g} / \mathrm{mL}$ propidium iodide $(\mathrm{PI})$ for 30 min at $4{ }^{\circ} \mathrm{C}$. Finally, the stained cells were analyzed by FACS. As for NPs concentration, cells were incubated with indicated concentration of FITC-labeled Pegylated Au NPs, Au-DUPA NPs, Au@DTX-DUPA NPs, respectively. After indicated incubated periods $(8,16,24 \mathrm{~h})$, the medium was removed and cells were harvested. Cell suspension was centrifuged, and the supernatant was removed. After that, the cell samples were resuspended by HBSS and were submitted to the procedure for measuring average FITC fluorescence intensities using FACS.

\section{Evaluation of Radiosensitive Efficacy In Vitro}

The enhancement of radiotherapy efficacy in vitro was evaluated by apoptosis related protein expression and colony formation assay. 22RV1 cells were incubated with indicated concentration $(30 \mu \mathrm{g} / \mathrm{mL}$, with respect to Au) of Pegylated Au NPs, Au-DUPA NPs, Au@DTX-DUPA NPs, respectively for $24 \mathrm{~h}$. Then, 4 Gy IR was given. Cells without treatment were set as control. Cells were collected and lysed with RIPA buffer. The supernatant was collected after centrifugation at $16,000 \mathrm{~g}$ at $4{ }^{\circ} \mathrm{C}$ for $15 \mathrm{~min}$. Protein concentration was measured with BCA method. Then protein lysis buffer was treated with $10 \%$ SDS-PAGE and transferred onto polyvinylidene difluoride (PVDF) membranes for western blot analysis, then blocked with $5 \%$ non-fat milk, and probed with primary antibodies at $4{ }^{\circ} \mathrm{C}$ overnight. The primary antibodies are as following: Cleaved PARP (1:1000, CST), $\beta$-Actin (1:5000, Abcam). The membrane was washed with TBST 3 times, and incubated with HRP linked secondary antibodies for $1 \mathrm{~h}$ at room temperature, followed by washing with TBST. Then, the membrane was incubated with ECL (Bio-rad) for $5 \mathrm{~min}$. Protein band was visualized by using a Bio-Rad Chemi-Doc MP imaging system. For colony formation assay, 22RV1 cells were seeded in 6-well plates at a concentration of $1 * 10^{4} /$ well and incubated with indicated concentration of Pegylated Au NPs, Au-DUPA NPs, or Au@DTX-DUPA NPs for $24 \mathrm{~h}$. Then, the medium was removed and cells were washed with HBSS to remove the non-internalized NPs. 4 Gy IR was given to each group. IR only group was set as reference Next, the cells were trypsinized, counted, and seeded into 6-well plates. After incubating for 12 days, the colony formation was washed with HBSS and fixed with $4 \%$ 
paraformaldehyde and $0.4 \%$ crystal violet solution in HBSS was added to stain the colonies. Then the number of them were counted to calculate the surviving fraction.

\section{Detection and Quantification of ROS}

22RV1 cells were seeded into 6-well plates and incubated with indicated concentration $(30 \mu \mathrm{g} / \mathrm{mL}$, with respect to Au) of Pegylated Au NPs, Au-DUPA NPs, Au@DTX-DUPA NPs for $24 \mathrm{~h}$. Cells received IR only were used as reference. After incubation, the medium was removed and cells were washed with HBSS. DCF-DA agent $(50 \mu \mathrm{M})$ in serum-free medium was added to each well and incubated for another 40 min. Then, the cells were washed with HBSS twice and received under 4Gy IR. Next, the cells were trypsinized, resuspended in HBSS. The average DCF-fluorescence intensity in cells were measured by FACS. As for imaging DCF-fluorescence, cells cultured in 96-well plates were washed with HBSS, added DCF-DA agent, radiated, and imaged with confocal laser scanning microscope by sequence.

\section{Detection and Quantification of DSBs}

$22 R V 1$ cells were incubated with indicated concentration $(30 \mu \mathrm{g} / \mathrm{mL}$, with respect to $\mathrm{Au})$ of Pegylated $\mathrm{Au}$ NPs, Au-DUPA NPs, Au@DTX-DUPA NPs for 24 h, before being subjected to 4Gy IR. Cells with IR only were used as reference. After IR, the cells were trypsinized and immersed in $4 \%$ paraformaldehyde fixation for 15 min and then washed with HBSS three times. After that, treating the cells with Triton X-100 for 30 min to damage their membranes. Next, the cells were soak in a blocking buffer ( $1 \%$ bovine serum albumin in tris-buffered saline solution) for $1 \mathrm{~h}$ and incubated with antihistone $\mathrm{\gamma H} 2 \mathrm{AX}$ mouse monoclonal antibodies (diluted 1:500 with HBSS) in the dark overnight at $4{ }^{\circ} \mathrm{C}$, followed by washing with HBSS three times. Then, they were further cultured with sheep anti-mouse secondary antibody (diluted 1:2000 with HBSS) for $2 \mathrm{~h}$ in dark and then washed with HBSS three times. Afterwards, $10 \mu \mathrm{L}$ Hoechst 33342 was used to stain the cells for $15 \mathrm{~min}$. Finally, the stained cells were analyzed with FACS. As for imaging the fluorescence, cells in 96-well plants were washed twice with cold HBSS after IR, fixed with 70\% ethanol for $2 \mathrm{~h}$, then treated with Triton X-100, soaked in a blocking buffer, incubated with antihistone $\mathrm{YH} 2 \mathrm{AX}$ mouse monoclonal antibodies, cultured with sheep anti-mouse secondary antibody, and observed with confocal laser scanning microscope by sequence.

\section{Biodistribution of NPs and In Vivo Anticancer Efficiency}

Xenograft tumors were inoculated in the right flank of male athymic nude mice ( 6 weeks old, 18-23g) by subcutaneous injection of $1 \times 10^{6} 22 \mathrm{RV} 1$ cells in $100 \mu \mathrm{L}$ of 1:1 (v/v) mixture of serum-free RPMI-1640 and matrigel solution. When tumor size reached about $100 \mathrm{~mm}^{3}$, tumor-bearing mice were divided randomly into 5 groups: control, RT only, Au NPs + RT, Au-DUPA NPs + RT, and Au@DTX-DUPA NPs + RT group. NPs were given to mice with the dose of $5 \mathrm{mg} / \mathrm{kg}$ (with respect to Au). 24h after injection of NPs, the mice received 6Gy electron beam under Varian True Beam system (SN1698). Machine operating at 6 $\mathrm{MeV}, 20 \mathrm{~cm}$ source subject distance, and $50 \mathrm{cGy} / \mathrm{min}$ dose rate. Only the tumor region was irradiated, as the remaining parts of the body were lead-shielded. All treatments were carried out only once. Tumor sizes and body weight were measured every day. Tumor volumes were calculated using the formula $\mathrm{V}=$ 
$0.5{ }^{*} a{ }^{*}{ }^{2}$, where "a" and "b" are the length and width of tumor, respectively. The data were collected until 14th day. Then, the mice received isoflurane anesthesia and were sacrificed by cervical dislocation. To evaluate the biodistribution of NPs, vital viscus (liver, lungs, heart, kidneys, spleen) and xenograft tumors of mice were collected at $12 \mathrm{~h}$ post injection of Au@DTX-DUPA NPs. Before analysis, all the tissue samples were stored at $-20^{\circ} \mathrm{C}$. Then, the samples were thawed, weighed, grinded, and then digested in 3 $\mathrm{mL}$ of aqua regia at $65^{\circ} \mathrm{C}$ overnight. Finally, the digested samples were diluted up to $20 \mathrm{~mL}$ with DI water and analyzed by ICP-MS.

\section{Statistics}

All experiments were performed in triplicates unless stated otherwise. All analyses were performed using R version 3.6.1 software (The R Foundation for Statistical Computing, Vienna, Austria; www.rproject.org). All numerical results are expressed as mean SD. Descriptive statistics and significant differences between groups were analyzed using two-tailed Student's t-tests, and the difference was considered significant if ${ }^{*} p<0.05$ and ${ }^{* \star} p<0.01$.

\section{Results And Discussion}

\section{Synthesis and Characterization of Au@DTX-DUPA NPs}

The synthesis strategy of the Au@DTX-DUPA nanosystem is shown in Figure 1a. The Au NPs were prepared by the classic Turkevich method in which gold chloride trihydrate $\left(\mathrm{HAuCl}_{4} \cdot 3 \mathrm{H}_{2} \mathrm{O}\right)$ was reduced by borane-tert-butylamine complex, resulting gold core diameter of $\sim 5 \mathrm{~nm}$ (Figure S1). Spherical shaped Au NPs were adopted due to the observation that compared with the Au NPs with other morphologies including spike or rod shapes, spherical NPs may result highest cellular uptake.[20] For Au NPs based radiosensitization, it has been proved that Au NPs would induce inhomogeneous dose distribution of Auger electrons within the immediate vicinity, depositing does of potentially thousands of Gy on the range of tens of $\mathrm{nm}$ [21] and the optimal radio-enhancement could be achieved when the distance is less than the mean range of the secondary electrons.[22] Therefore, whether Au NPs can enter into cells is an important factor to determine the overall level for the radio-enhancement. Moreover, it has been reported that $5 \mathrm{~nm}$ PEG-coated Au NPs have relatively smaller impacts on blood cells, hepatic functions, and renal functions.[23] The as-synthesized hydrophobic Au NPs would then undergo the PEGylation process, for the purpose of amphiphilic phase transition (Figure S2) and also to endow the Au NPs with the longcirculating property. Figure $1 \mathrm{~b}$ shows the light gray halo surrounding the Au NPs, confirming the successful PEGylation process (Figure 1b). Afterwards, DUPA(OtBu)-OH, a precursor of DUPA with protective groups, was modified on surface of PEGylated Au NPs for the targeting purpose as previously reported with minor modification.[24] The protective groups of DUPA(OtBu)-OH were removed by trifluoroacetic acid. Agarose gel electrophoresis was then performed to demonstrate the deprotecting of DUPA(OtBu)-OH and also successful coating of DUPA. As demonstrated in Figure 1c, compared with the vitamin B12 (electroosmotic flow tracer) and Pegylated Au NPs, Au-DUPA NPs could migrate to the anode due to the electronegativity of carboxyl groups within DUPA molecules. Meanwhile, the synchronism of 
the migration by Au-DUPA NPs could suggest the rather uniform size and charge of these NPs. Furthermore, Fourier transform infrared (FTIR) spectra also verified the DUPA coating through the presence of $\mathrm{C}=0$ peaks at $1729 \mathrm{~nm}^{-1}$ (Figure $1 \mathrm{~d}$ ).

\section{DTX Loading and In Vitro Release Profile}

DTX molecules were encapsulated into the PEG coronal of the PEGylated Au-DUPA NPs through the noncovalent interaction to construct the Au@DTX-DUPA NPs. To evaluate the loading capacity of Au-DUPA NPs for DTX, UV/Vis analysis was performed. As shown in Figure 2a, the typical band of DTX in water appeared at $231 \mathrm{~nm}$. When the weight ratio of DTX to Au-DUPA NPs is more than $1 / 25$, the typical band appeares. By contrast, the typical band would disappear when the weight ratio of DTX to Au-DUPA NPs is less than $1 / 25$, suggesting that all the DTX molecules could be successfully encapsulated within the PEG coronal. The weight ratio of DTX to Au NPs was 1/4000 throughout the investigation, therefore ensured that all the DTX molecules have been encapsulated with the NPs. The final nanosystem were purified through a $0.22 \mu \mathrm{m}$ syringe filter and measured by dynamic light scattering. As demonstrated in Figure $2 b$, the average diameter of final NPs is $11.9( \pm 2.8) \mathrm{nm}$. The cumulative release behavior of DTX from the Au@DTX-DUPA is shown in Figure S3. It can be noticed that there is an initial burst release in the first five hours, during which $42.25 \%$ of DTX is released from the NPs. In the following period, DTX is released by a tardy manner. Such a release profile can be categorized as a biphasic pattern and this kind of two-phase behavior has already been observed for various drug loaded NPs, for which various parameters such as drug loading, conjugation as well formulation composites were found to influence the release.[25]

\section{Cellular Uptake and Cytotoxicity Assay}

Two kinds of human PCa cell lines, 22RV1and PC3 cell lines, namely, with or without PSMA expression were adopted and the cellular uptake for Au-DUPA NPs was compared. Before the investigation, the expression of PSMA in both cell lines was verified by immunohistochemistry. As shown in Figure S4, the brown stain which displays on the membrane of 22RV1 (PSMA+) cells while not on PC3 cells (PSMA-), confirming the positive and negative expression of PSMA in these two cell lines, respectively. Then, 22RV1 and PC3 cells were incubated with FITC-labeled Au-DUPA NPs for 24h. Confocal fluorescence images show that fluorescence intensity of 22RV1 cells is much stronger than that of PC3 cells (Figure 2c), suggesting the higher internalization behavior of Au-DUPA NPs in the 22RV1 cells. ICP-MS result also shows that 22RV1 cells had about 2.4 times higher Au content than PC3 cells (Figure 2d). All the results confirm the higher cellular uptake of DUPA modified Au NPs in the PCa cells with PSMA expression. Au NPs internalized within the cells mainly through endocytosis [26] and DUPA could interact with the specific receptor on the cell membrane of 22RV1 to form an antibody-receptor conjugation. Therefore, 22RV1 cells could uptake much more NPs via the receptor-mediated endocytosis.

The in vitro cytotoxicity of Au-DUPA NPs was evaluated by co-incubating the murine fibroblast cell lines (L929) with the NPs under various concentrations. It can be noticed that Au-DUPA NPs possessing low cytotoxicity and ideal in vitro biocompatibility. Within the range of concentration levels up to $125 \mu \mathrm{g} / \mathrm{mL}$, 
the values for the cell viability maintain constant, indicating negligible effect of the NPs on the cell viability (Figure 2e). The concentrations for EC50 (50\% of maximal effect) of Au@DTX-DUPA NPs and free DTX on 22RV1 cells were further evaluated and compared. The results are shown in Figure 2f, where both formulations exhibit dose-dependent cytotoxic effect. After calculation, the EC50 values for Au@DTX-DUPA and free drug formulations on 22RV1 cells are 1.2nM and 2.2nM, respectively. It has been confirmed that the working mechanism of DTX is based on the binding with the $\beta$-tubulin subunit of polymerized tubulin dimers. Therefore, effective cellular uptake of the drug is the priority for the drug to take actions. By contrast with the involvement of ATP-dependent efflux pumps and special transporters for DTX influx, Au@DTX-DUPA NPs can deliver DTX to the tumor cells though receptor-mediated endocytosis, thus lead to the enhanced cytotoxic effect and lower EC50 compared with the free drug. Moreover, due to the interaction between DTX and P-glycoprotein (P-gp), a key protein overexpressed by cancer cell lines to increase drug efflux, intracellular drug concentration would be further reduced.[27] Similar results were also noticed on the PSMA coated mesoporous silica NPs for DTX selective intracellular delivery to PCa cells, as higher cytotoxic activity of the nanosystem could be achieved as compared with free DTX formulation.[28] It is worth noting that in the current study, DTX was adopted as a radiosensitizer agent rather than chemotherapeutic drug. Therefore, in the following in vitro experiments, 30 $\mu \mathrm{g} / \mathrm{mL}$ Au@DTX-DUPA containing 1.2nM DTX was applied for avoiding too severely direct cell killing effect.

\section{In vitro Evaluation of the Radiosensitive Effect}

Cleavage of poly (ADP-ribose) polymerase (PARP) was applied to evaluate the cell apoptosis among various groups under different treatments. It can be noticed in Figure $3 a$ that while unnoticeable PARP expression in the control group, all the other treatments would induce the PARP expression. Compared with the treatment of irradiation (IR) only, the co-incubation with Au NPs with different coatings would promote the PARP expression. Moreover, DUPA coating would result in more remarkable PARP expression than Pegylated Au NPs, and Au@DTX-DUPA NPs possess the most significant performance among all the treatments for PARP expression. Furthermore, the colony formation was carried out to investigate the in vitro radiosensitization effect by Au NPs with different coatings. Similar to the western blotting investigation, it is evident from Figure $3 b$ that Au NPs could decrease the colony forming of 22RV1 cells in a coating dependent manner compared to control group. Once again, the trend that Au-DUPA NPs have better performance than Pegylated Au NPs, and most significant effect happened to Au@DTX-DUPA NPs could be observed. Cell survival fractions under various IR doses and different treatments are shown in Figure $3 \mathrm{c}$, and the results are in consistent with the colony formation observation. For instance, under 4Gy $\mathrm{IR}$, there is $45.0 \%$ colony formation of $22 \mathrm{RV} 1$ cells in the IR only group, while there are only $39.7 \%, 30.3 \%$ and $14.3 \%$ cell survival rates in the Pegylated Au, Au-DUPA and Au@DTX-DUPA NPs groups, respectively. Moreover, the SER50 (defined as the ratio of survival fractions without and with NPs at a survival rate of $50 \%$ ) value of Au@DTX-DUPA NPs calculated by the survival fraction curves was 1.73, which is much higher than that of Au-DUPA NPs or Pegylated Au NPs (1.36 and 1.17). In addition, we compared the colony formation inhibitive efficacy between Au@DTX-DUPA NPs and Au-DUPA NPs at gradient concentration under 4 Gy IR. The inhibitive efficiency of both NPs is concentration dependent. Compared 
with Au-DUPA NPs, Au@DTX-DUPA NPs with lower concentration could achieve comparable results (Figure S5). All the findings confirm the remarkable contribution of DTX to the radiosensitization effect of Au@DTX-DUPA NPs.

\section{G2/M Phase Arrest and Cascade Enrichment of NPs Internalization}

As shown in Figure 3d, the proportion of cells in G2/M phase is increasing with incubation time in both free DTX and Au@DTX-DUPA NPs groups, but no such effect could be observed in Au-DUPA NPs group. After $24 \mathrm{~h}$ incubation, the proportions of cells in G2/M phase in free DTX group and Au@DTX-DUPA NPs group are 3.0 times and 3.8 times of that in Au-DUPA NPs group. As an effective microtubule-targeted drug, DTX could delay cell division by accelerating the polymerization of microtubule proteins and then cause excessive microtubule formation and stabilization to selectively induce G2/M phase arrest. The better performance of Au@DTX-DUPA NPs than that of free DTX could be explained by more DTX cellular uptake by NPs formulation, as discussed earlier. It has been widely acknowledged that cell cycle has significant effect on the outcome of irradiation. as mitotic cells are more hypersensitive to irradiation. Mitotic phase could effectively inactivate DSBs repair by inhibiting telomere fusion. $[29,30]$ Therefore, arresting more cells in pre-mitotic (G2) and mitotic phases (M) would make the cells more sensitive to IR.

Another beneficial contribution from G2/M phase arrest can be revealed from the higher intracellular NPs concentration, as shown in Figure 3e. The fluorescence intensity in Pegylated Au NPs and Au-DUPA NPs groups presents a growing trend within $16 \mathrm{~h}$ incubation, whereas it shows a downward trend after $24 \mathrm{~h}$ incubation. However, the fluorescence intensity of Au@DTX-DUPA NPs group is stronger than those of the other two groups at all incubated periods and maintained at a high level after $24 \mathrm{~h}$ incubation. Intracellular NPs concentration could be diluted by cell division, as the internalized NPs could be distributed into the daughter cells during the division.[31, 32] Cells at G2/M phases arrested by DTX have not yet divided, therefore high retention of the NPs within the cells. Apart from that, cells in G2/M phases are normally associated with higher NPs uptake because it has been proved that the transport associated membrane proteins are highly expressed in G2/M phases than other cell cycle phases.[33-36] Based on the two points, the cascade enhanced retention and enrichment of NPs within the cells could be achieved.

\section{ROS and DSBs under IR}

DCFH-DA assay was adopted to evaluate the ROS production. As shown in Figure 6a, while faint green fluorescent spots exist in cells under IR only, more bright fluorescent images can be achieved by cell coincubating with various NPs in the sequence of Au@DTX-DUPA NPs > Au@DUPA NPs > Pegylated Au NPs (Figure 4a). Fluorescent intensity quantified by FACS is shown and compared in Figure $4 b$, and the results indicate that Pegylated Au NPs, Au@DUPA NPs, and Au@DTX-DUPA NPs induces 1.2, 1.6, and 2.5 times higher ROS than IR only group, respectively. As one of the primary killing pathways of IR, ROS generated by the radiolysis of water could induce cell death either by interacting with biological molecules directly or by exerting oxidative stress indirectly.[37] The higher concentration of Au@DTX-DUPA NPs within cells could lead to more secondary electron under IR and thus to produce higher level of ROS. In addition, DTX 
can elicit ROS production from NADPH oxidase.[38] Beyond that, cytochrome P450 can metabolize DTX to generate hydroxide radicals.[39] All of these could account for the promoted ROS production by Au@DTX-DUPA NPs.

Degree of DSBs under different treatments was evaluated by $\mathrm{Y}-\mathrm{H} 2 \mathrm{AX}$ staining. It can be revealed that the phenomena are quite in consistent with the results of ROS production, as demonstrated in Figure 4c. DSBs, indicated by the fluorescent images, become more remarkable in the group sequence of Au@DTXDUPA NPs > Au@DUPA NPs > Pegylated Au NPs > IR only. Quantitative analysis by FACS also supported the observation, as demonstrated in Figure $4 \mathrm{~d}$ that Pegylated Au NPs group, Au-DUPA NPs group, and Au@DTX-DUPA NPs group has 1.4, 2.1, and 3.3 times higher DSBs than IR only group, respectively. DNA damage accounts for another important working mechanism of IR induced cell killing and there are several types of DNA damage may involved, including single strand breaks, DNA base modifications, and DSBs.[40] Among these, DSBs are considered to be the most detrimental factor for clonogenic cell killing. [41] There are two possible reasons responsible for the better performance of Au@DTX-DUPA NPs for DSBs. First, more ROS could directly induce increased DNA damage through oxidizing nucleoside bases (e.g. formation of 8-oxo guanine). Second, DTX can enter into nucleus and bond to double-stranded DNA to form a stable DTX-topoisomerase II complex that prevents proteins from repairing DNA damage.[42] The observation that the as-synthesized Au@DTX-DUPA NPs would greatly aggravates the ROS and DSBs under IR could provide an underlying basis as effective radiosensitizers.

\section{In Vivo Evaluation of the Radiosensitive Effect}

22RV1 tumor bearing xenograft nude mice were grouped for different treatments and the tumor volumes were recorded and shown in Figure 5a-b. Compared with the mice in control group which only received saline injection, the growth of all tumors in other groups are inhibited to varying degrees. Specifically, the mice treated with Au-DUPA NPs + RT have better response than those with Pegylated Au NPs + RT. And the Au@DTX-DUPA NPs+ RT shows the best antitumor efficacy among all treatments, with tumor size increasing by only $20 \%$ on 14 days after treatment. Meanwhile, the weight changes of mice with different treatments were monitored (Figure 5c). There is no significant weight change in mice treated with Au@DTX-DUPA NPs + RT, Au-DUPA NPs + RT, or Pegylated Au NPs + RT, while there is significant weight loss in those treated with RT alone and control group. On the $15^{\text {th }}$ day after treatments, all mice received isoflurane anesthesia and were sacrificed by cervical dislocation. The vital viscus (including the heart, liver, spleen, lung, and kidney) and tumor were collected. The proliferative capacity of tumors was evaluated with Ki67 assay. As shown in Figure 5e, the expression of Ki67 is significantly inhibited in Au@DTX-DUPA NPs + RT group compared with other groups. The impairment of vital viscus was evaluated by histopathological analysis with H\&E assay (Figure S6). Neither prominent damage nor inflammation are observed in any of the viscus of the treated mice, indicating that these NPs did not cause obvious visceral toxicity in the animals.

NPs biodistribution were evaluated by ICP-MS and the results are shown in Figure S7. It could be revealed that despite that remarkable amount of Au NPs could be retained within tumor tissue with Au content of 
$27 \mu \mathrm{g} / \mathrm{g}$, there is still considerable concentration of Au accumulated in the reticuloendothelial system, mostly liver and spleen. Further on, special attention has been paid on the retention ability by tumor tissues on the Au@DTX-DUPA NPs and Au-DUPA NPs. As shown in Figure 5d, $6 \mathrm{~h}$ after injection, the Au concentration in 22RV1 xenograft tumors is similar between Au@DTX-DUPA NPs and Au-DUPA NPs groups. However, a decreased Au accumulation in the tumors treated with Au-DUPA NPs could be observed at $24 \mathrm{~h}$ after injection, while Au content keeps stable in the mice tumors treated with Au@DTXDUPA NPs. Furthermore, the Au concentration in tumors of Au@DTX-DUPA NPs group is 1.5 times higher than that of Au@-DUPA group. Our in vitro investigation has demonstrated that due to the G2/M phases arrest by Au@DTX-DUPA NPs, accumulation of NPs inside cells could be effectively increased. The results demonstrated in Figure $5 \mathrm{e}$ also prove such performance can also be achieved in vivo. Except for the active targeting effect by DUPA, the loading of DTX can also further enhance the retention of Au NPs by cell cycle arrest.

\section{Conclusions}

In summary, PSMA-targeted DTX loaded Au NPs were successfully synthesized and demonstrated as an all-purpose radiosensitization with great potential for clinical translation. The as-synthesized NPs can selectively target to PCa cells with PSMA expression. Results of in vitro cellular uptake assay demonstrated significantly higher NPs uptake in PSMA + 22RV1 cells than in PSMA - PC3 cells, therefore enhanced dose deposition effect by Au NPs could be fully guaranteed. Moreover, Au@DTX-DUPA NPs could promote G2/M phases arrest for more sensitive of the PCa cells to IR. Meanwhile, cell-cycle arrest would further induce cascade retention and enrichment of the NPs within the cells, which would strengthen the dose deposition effect. Furthermore, ROS generation and DSBs could be greatly promoted by the Au@DTX-DUPA NPs under IR, thereby to provide an underlying basis for effective radiosensitizers. Promising results from in vitro and in vivo investigations confirmed the as-synthesized Au@DTX-DUPA NPs as an effective nano-radiosensitizer with ideal safety. Once again, it was noting that all the moieties within the NPs have been approved by FDA for the purpose of PCa treatment. Though more detailed and systemic validation is needed, the rather simple structure by the facile protocol makes the nanosystem based on first-line drug repurposing highly attractive for clinical translation.

Supporting Information. Supplement materials

\section{Abbreviations}

PSMA, prostate specific membrane antigen; DTX, docetaxel; Au NPs, Au nanoparticles; Au-DUPA NPs, DUPA modified Au nanoparticles; Au@DTX-DUPA NPs, docetaxel loaded DUPA modified Au nanoparticles.

\section{Declarations}

Ethics approval and consent to participate Not applicable. 
Consent for publication All the authors agree with the publication.

Availability of data and materials All data generated or analysed during this study are included in this published article.

\section{Author Contributions}

LY. Zhao, M. Liu and JY. Wang conceived and directed the research project. XX. Guo and ZH. G prepared and characterized the nano-composites. XX. Guo and M. Wu tested the detailed biological properties of samples. XX. Guo, YJ. Chi and WS. Xie carried out the in vitro cell experiment including biocompatibility and cytotoxicity. XX. Guo and XD. Sun colony formation assay to evaluate radiosensitive efficacy. QZ. Zhong formulated radiotherapy regimen. XX. Guo, JS Lu, and XM. Wang performed the animal experiments to evaluated the in vivo anticancer efficiency. XX. Guo analyzed the experimental results and wrote the paper. All authors approve the final version of the manuscript.

\section{Author information}

Corresponding Author

*E-mail: wangjy@bjhmoh.cn (JY. Wang)

*E-mail: liuming19731029@163.com (M. Liu)

*E-mail: lyzhao@mail.tsinghua.edu.cn (LY. Zhao)

Competing interests The authors declare no competing financial interest.

Funding This study was supported by grants of the Beijing Municipal Science and Technology Project (Nos. Z201100005620007囚and the National Natural Science Foundation of China (Nos. $519711681671829)$

\section{Acknowledgment No}

\section{References}

1. Rawla P. Epidemiology of prostate cancer. World journal of oncology. 2019;10:63.

2. Global, regional, and national comparative risk assessment of 79 behavioural, environmental and occupational, and metabolic risks or clusters of risks, 1990-2015: a systematic analysis for the Global Burden of Disease Study 2015. Lancet 2016, 388:1659-1724.

3. Haglind E, Carlsson S, Stranne J, Wallerstedt A, Wilderäng U, Thorsteinsdottir T, Lagerkvist M, Damber JE, Bjartell A, Hugosson J, et al. Urinary Incontinence and Erectile Dysfunction After Robotic Versus Open Radical Prostatectomy: A Prospective, Controlled, Nonrandomised Trial. Eur Urol. 2015;68:21625. 
4. Oake JD, Shiff B, Harasemiw O, Tangri N, Ferguson TW, Bhindi B, Saranchuk JW, Bansal RK, Drachenberg DE, Nayak JG. The Comparative Outcomes of Radical Prostatectomy versus Radiotherapy for Non-metastatic Prostate Cancer: A Longitudinal, Population-Based Analysis. J Urol 2020:101097ju0000000000000805.

5. Cornford P, van den Bergh RCN, Briers E, Van den Broeck T, Cumberbatch MG, De Santis M, Fanti S, Fossati N, Gandaglia G, Gillessen S, et al. EAU-EANM-ESTRO-ESUR-SIOG Guidelines on Prostate Cancer. Part II-2020 Update: Treatment of Relapsing and Metastatic Prostate Cancer. Eur Urol. 2021;79:263-82.

6. Xiaoxiao G, Min, Liu, Huimin, Hou, Shenjie X, Zhang Y. Impact of prostate cancer radiotherapy on the biological behavior and specific mortality of subsequent bladder cancer. International Journal of Clinical Oncology 2019.

7. Wei Q, He J, Wang S, Hua S, Qi Y, Li F, Ling D, Zhou M. Low-dose X-ray enhanced tumor accumulation of theranostic nanoparticles for high-performance bimodal imaging-guided photothermal therapy. J Nanobiotechnology. 2021;19:155.

8. Bai L, Jiang F, Wang R, Lee C, Wang H, Zhang W, Jiang W, Li D, Ji B, Li Z, et al. Ultrathin gold nanowires to enhance radiation therapy. J Nanobiotechnology. 2020;18:131.

9. Voorwerk L, Slagter M, Horlings HM, Sikorska K, van de Vijver KK, de Maaker M, Nederlof I, Kluin RJC, Warren S, Ong $\mathrm{S}$, et al. Immune induction strategies in metastatic triple-negative breast cancer to enhance the sensitivity to PD-1 blockade: the TONIC trial. Nat Med. 2019;25:920-8.

10. Pujade-Lauraine E, Fujiwara K, Dychter SS, Devgan G, Monk BJ. Avelumab (anti-PD-L1) in platinumresistant/refractory ovarian cancer: JAVELIN Ovarian 200 Phase III study design. Future Oncol. 2018;14:2103-13.

11. Xie J, Gong L, Zhu S, Yong Y, Gu Z, Zhao Y. Emerging Strategies of Nanomaterial-Mediated Tumor Radiosensitization. Adv Mater. 2019;31:e1802244.

12. Potier P. Relationships between the structure of taxol analogues and their antimitotic acitivity. J Med Chem. 1991;3:992-8.

13. Rosenthal SA, Hu C, Sartor O, Gomella LG, Amin MB, Purdy J, Michalski JM, Garzotto MG, Pervez N, Balogh AG, et al. Effect of Chemotherapy With Docetaxel With Androgen Suppression and Radiotherapy for Localized High-Risk Prostate Cancer: The Randomized Phase III NRG Oncology RTOG 0521 Trial. J Clin Oncol. 2019;37:1159-68.

14. Zhang Y, Huang F, Ren C, Liu J, Yang L, Chen S, Chang J, Yang C, Wang W, Zhang C. Enhanced radiosensitization by gold nanoparticles with acid-triggered aggregation in cancer radiotherapy. Advanced Science. 2019;6:1801806.

15. Rastinehad AR, Anastos H, Wajswol E, Winoker JS, Sfakianos JP, Doppalapudi SK, Carrick MR, Knauer CJ, Taouli B, Lewis SC, et al. Gold nanoshell-localized photothermal ablation of prostate tumors in a clinical pilot device study. Proc Natl Acad Sci U S A. 2019;116:18590-6.

16. Gardner TA, Fletcher JW, Ko S-C, Low PS, Ratliff TL. Abstract LB-90: DUPA-99mTc localizes to prostate cancer in men with locally advanced and metastatic disease. AACR; 2013. 
17. Ju Y, Zhang H, Yu J, Tong S, Tian N, Wang Z, Wang X, Su X, Chu X, Lin J, et al. Monodisperse Au$\mathrm{Fe}(2) \mathrm{C}$ Janus Nanoparticles: An Attractive Multifunctional Material for Triple-Modal Imaging-Guided Tumor Photothermal Therapy. ACS Nano. 2017;11:9239-48.

18. Lv Q, Yang J, Zhang R, Yang Z, Yang Z, Wang Y, Xu Y, He Z. Prostate-Specific Membrane Antigen Targeted Therapy of Prostate Cancer Using a DUPA-Paclitaxel Conjugate. Mol Pharm. 2018;15:1842-52.

19. Roy J, Nguyen TX, Kanduluru AK, Venkatesh C, Lv W, Reddy PV, Low PS, Cushman M. DUPA conjugation of a cytotoxic indenoisoquinoline topoisomerase I inhibitor for selective prostate cancer cell targeting. J Med Chem. 2015;58:3094-103.

20. Ma N, Wu F-G, Zhang X, Jiang Y-W, Jia H-R, Wang H-Y, Li Y-H, Liu P, Gu N, Chen Z. Shape-dependent radiosensitization effect of gold nanostructures in cancer radiotherapy: comparison of gold nanoparticles, nanospikes, and nanorods. ACS Applied Materials interfaces. 2017;9:13037-48.

21. Butterworth KT, McMahon SJ, Currell FJ, Prise KM. Physical basis and biological mechanisms of gold nanoparticle radiosensitization. Nanoscale. 2012;4:4830-8.

22. Gholami YH, Maschmeyer R, Kuncic Z. Radio-enhancement effects by radiolabeled nanoparticles. Sci Rep. 2019;9:14346.

23. Zhang XD, Wu D, Shen X, Liu PX, Yang N, Zhao B, Zhang H, Sun YM, Zhang LA, Fan FY. Sizedependent in vivo toxicity of PEG-coated gold nanoparticles. Int J Nanomedicine. 2011;6:2071-81.

24. Roy J, Nguyen TX, Kanduluru AK, Venkatesh C, Lv W, Reddy PN, Low PS, Cushman M. DUPA conjugation of a cytotoxic indenoisoquinoline topoisomerase I inhibitor for selective prostate cancer cell targeting. Journal of medicinal chemistry. 2015;58:3094-103.

25. François A, Laroche A, Pinaud N, Salmon L, Ruiz J, Robert J, Astruc D. Encapsulation of docetaxel into PEGylated gold nanoparticles for vectorization to cancer cells. ChemMedChem. 2011;6:2003-8.

26. Sindhwani S, Syed AM, Ngai J, Kingston BR, Maiorino L, Rothschild J, MacMillan P, Zhang Y, Rajesh NU, Hoang T. The entry of nanoparticles into solid tumours. Nat Mater. 2020;19:566-75.

27. O'Neill AJ, Prencipe M, Dowling C, Fan Y, Mulrane L, Gallagher WM, O'Connor D, O'Connor R, Devery A, Corcoran $\mathrm{C}$, et al. Characterisation and manipulation of docetaxel resistant prostate cancer cell lines. Mol Cancer. 2011;10:126.

28. Mukherjee A, Darlington T, Baldwin R, Holz C, Olson S, Kulkarni P, DeWeese TL, Getzenberg RH, Ivkov $\mathrm{R}$, Lupold SE. Development and screening of a series of antibody-conjugated and silica-coated iron oxide nanoparticles for targeting the prostate-specific membrane antigen. ChemMedChem. 2014;9:1356-60.

29. Orthwein A, Fradet-Turcotte A, Noordermeer SM, Canny MD, Brun CM, Strecker J, Escribano-Diaz C, Durocher D. Mitosis inhibits DNA double-strand break repair to guard against telomere fusions. Science. 2014;344:189-93.

30. Giunta S, Belotserkovskaya R, Jackson SP. DNA damage signaling in response to double-strand breaks during mitosis. J Cell Biol. 2010;190:197-207. 
31. Kim JA, Åberg C, Salvati A, Dawson KA. Role of cell cycle on the cellular uptake and dilution of nanoparticles in a cell population. Nature nanotechnology. 2012;7:62-8.

32. Rees P, Wills JW, Brown MR, Barnes CM, Summers HD. The origin of heterogeneous nanoparticle uptake by cells. Nature communications. 2019;10:1-8.

33. Boucrot $E$, Kirchhausen $T$. Endosomal recycling controls plasma membrane area during mitosis. Proc Natl Acad Sci U S A. 2007;104:7939-44.

34. Walczyk D, Bombelli FB, Monopoli MP, Lynch I, Dawson KA. What the cell "sees" in bionanoscience. J Am Chem Soc. 2010;132:5761-8.

35. Jiang W, Kim BY, Rutka JT, Chan WC. Nanoparticle-mediated cellular response is size-dependent. Nat Nanotechnol. 2008;3:145-50.

36. Liu Y, Chen W, Zhang P, Jin X, Liu X, Li P, Li F, Zhang H, Zou G, Li Q. Dynamically-enhanced retention of gold nanoclusters in HeLa cells following X-rays exposure: A cell cycle phase-dependent targeting approach. Radiother Oncol. 2016;119:544-51.

37. Zhang J, Wang X, Vikash V, Ye Q, Wu D, Liu Y, Dong W. ROS and ROS-Mediated Cellular Signaling. Oxid Med Cell Longev. 2016;2016:4350965.

38. Gut I, Danielova V, Holubova J, Souček P, Klučková H. Cytotoxicity of cyclophosphamide, paclitaxel, and docetaxel for tumor cell lines in vitro: effects of concentration, time and cytochrome P450catalyzed metabolism. Arch Toxicol. 2000;74:437-46.

39. Cao D, Qiao B, Ge Z, Yuan Y. Amplification loop cascade for increasing caspase activity induced by docetaxel. Journal of cellular biochemistry. 2005;96:810-20.

40. Helleday T, Petermann E, Lundin C, Hodgson B, Sharma RA. DNA repair pathways as targets for cancer therapy. Nat Rev Cancer. 2008;8:193-204.

41. Banáth JP, Olive PL. Expression of phosphorylated histone $H 2 A X$ as a surrogate of cell killing by drugs that create DNA double-strand breaks. Can Res. 2003;63:4347-50.

42. Hill BT, Whelan RD, Shellard SA, McClean S, Hosking LK. Differential cytotoxic effects of docetaxel in a range of mammalian tumor cell lines and certain drug resistant sublinesin vitro. Investig New Drugs. 1994;12:169-82.

\section{Figures}


(a)

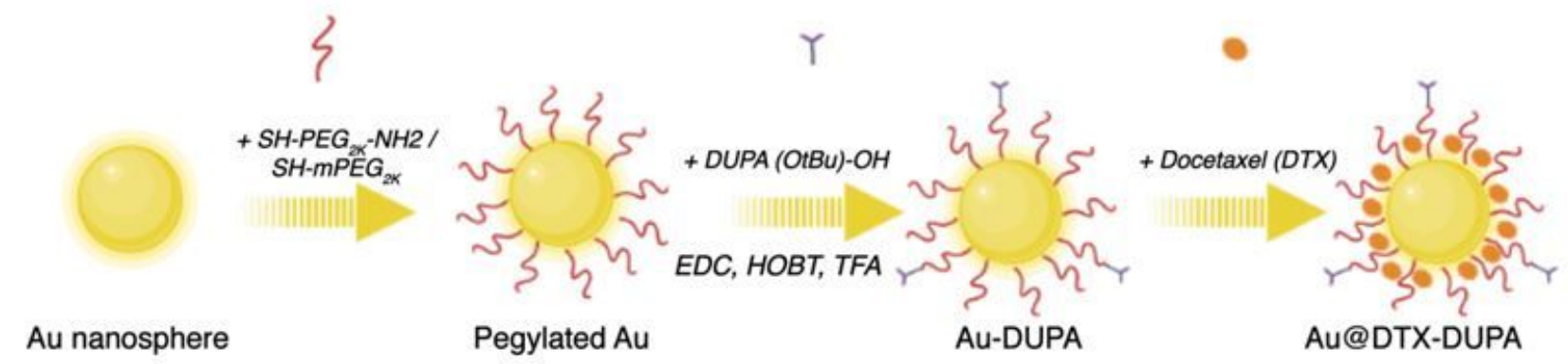

(b)

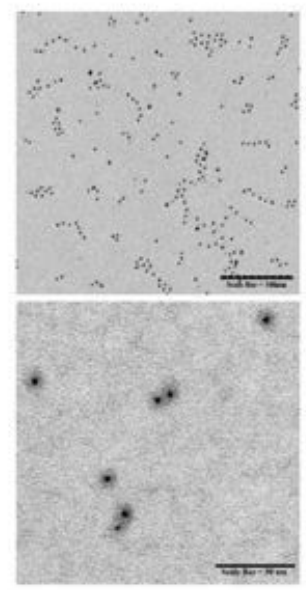

(c)

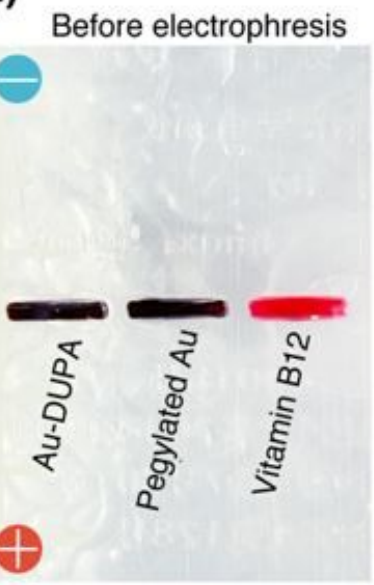

(d)

20 min after electrophresis

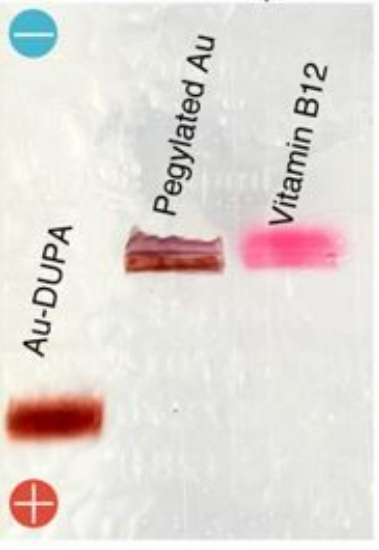

\section{Figure 1}

(a) Schematic of Au@DTX-DUPA NPs synthesis. (b) TEM images of Pegylated Au NPs unstained and stained by $2 \%$ phosphotungstic acid. (c) Agarose gel electrophoresis of Au-DUPA NPs, Pegylated Au NPs, and vitamin B12 in TAE buffer ( $\mathrm{pH}=8.5)$. (d) FTIR spectra of Pegylated Au NPs and Au-DUPA NPs. 
(a)

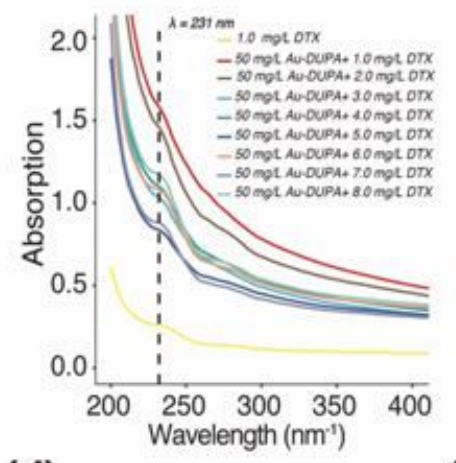

(d)

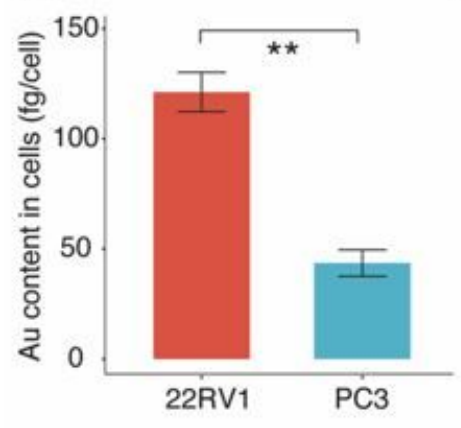

(b)

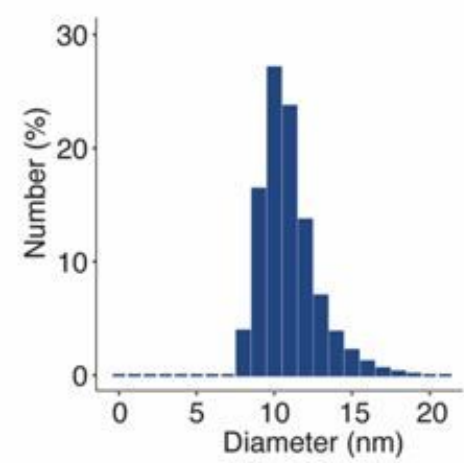

(e)

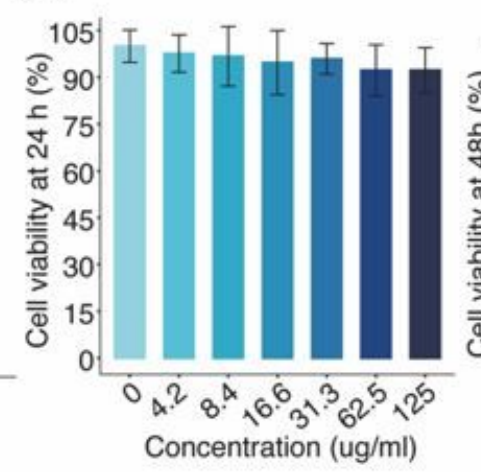

(c)

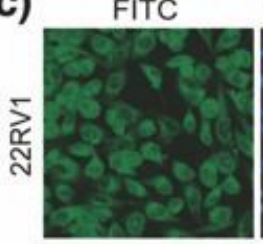

Hoechst33342

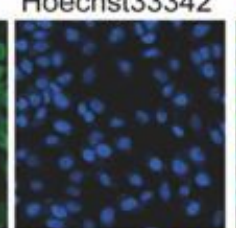

Merged
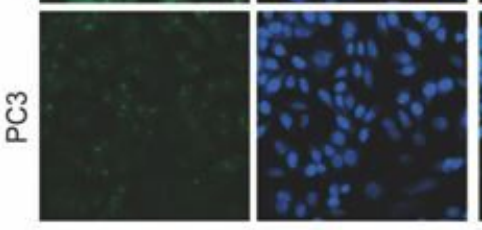

(f)

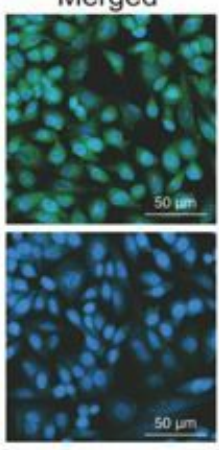

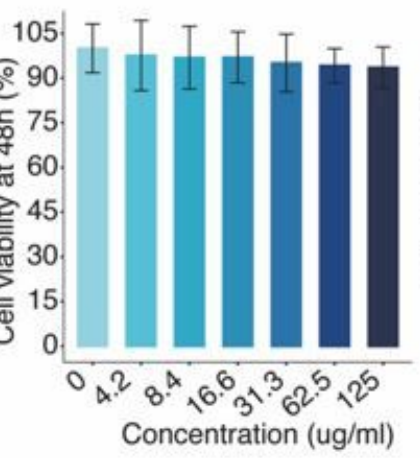

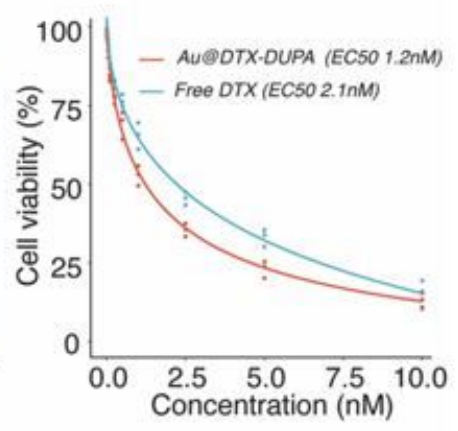

Figure 2

(a) UV/Vis analysis for various weight ratio of DTX/Au-DUPA NPs in $\mathrm{H} 2 \mathrm{O}$ solution. The spectrum of free DTX was set as reference. (b) Distribution of the hydrodynamic diameters of Au@DTX-DUPA NPs. (c) Confocal fluorescence images of 22RVI and PC3 cells, which incubated with FITC-labeled Au-DUPA NPs for $24 \mathrm{~h}$. FITC-labeled NPs show green fluorescence and Hochest 33342 with blue fluorescence is used for nuclear staining. (d) Quantitative Au content of 22RV1 and PC3 cells incubated with FITC-labeled AuDUPA NPs for $24 \mathrm{~h}$ by ICP-MS. Data are represented as mean \pm SD $(n=5)$. (e) Relative cell viability of L929 cells incubated with different concentrations of Au-DUPA NPs for $24 \mathrm{~h}$ and $48 \mathrm{~h}$. Data are represented as mean $\pm S D(n=5)$. (f) Relative cell viability 22RV1 cells treated with different concentrations of free DTX or Au@DTX-DUPA NPs to determine the concentration for EC50. Data are represented as mean $\pm S D(n=3)$. P values were calculated using the two-tailed unpaired Student's t-test. ** $\mathrm{P}<0.01$. 


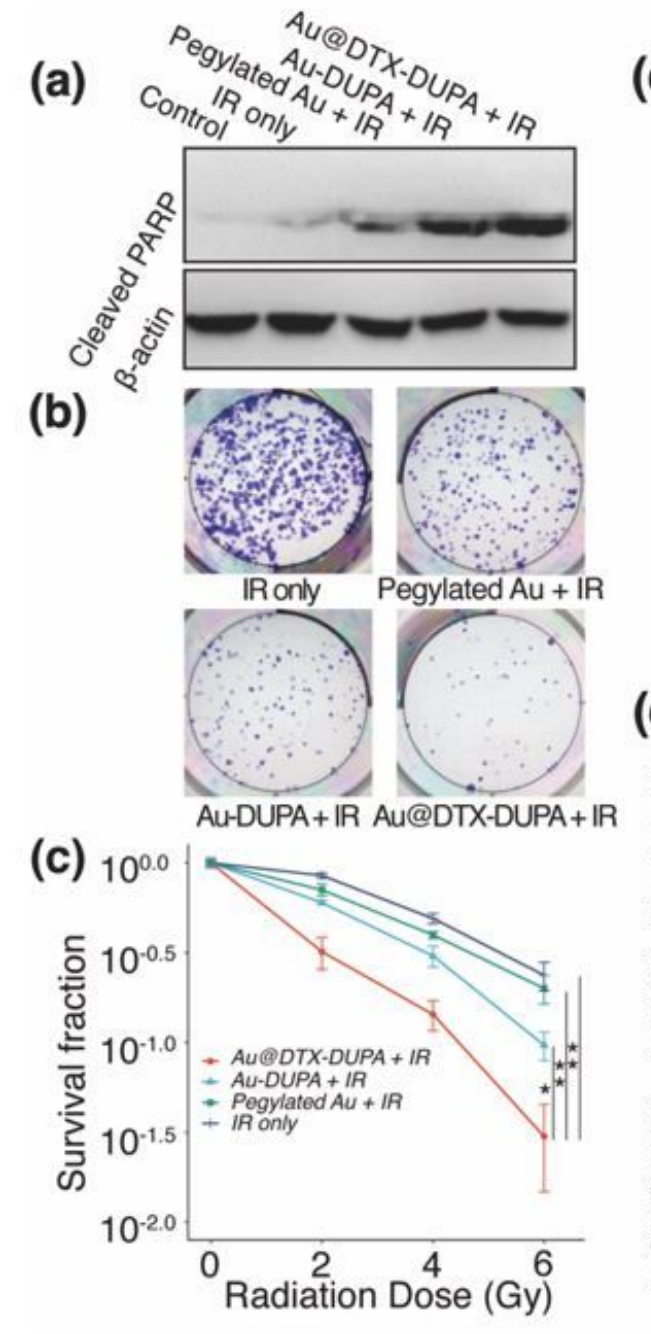

(d)
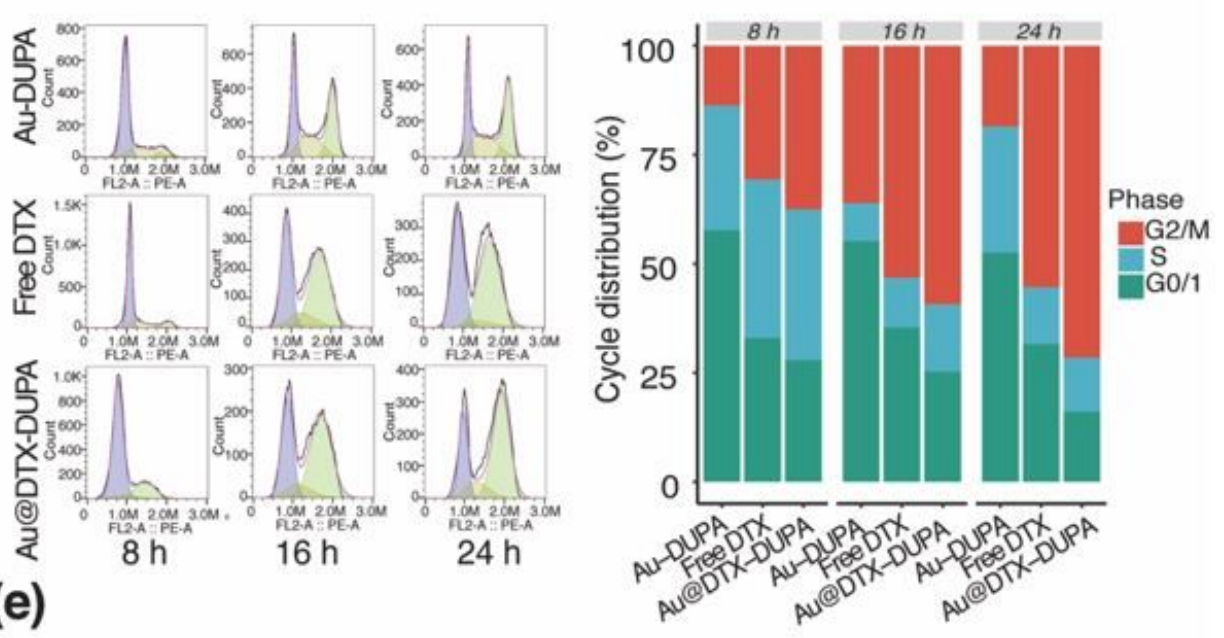

(e)
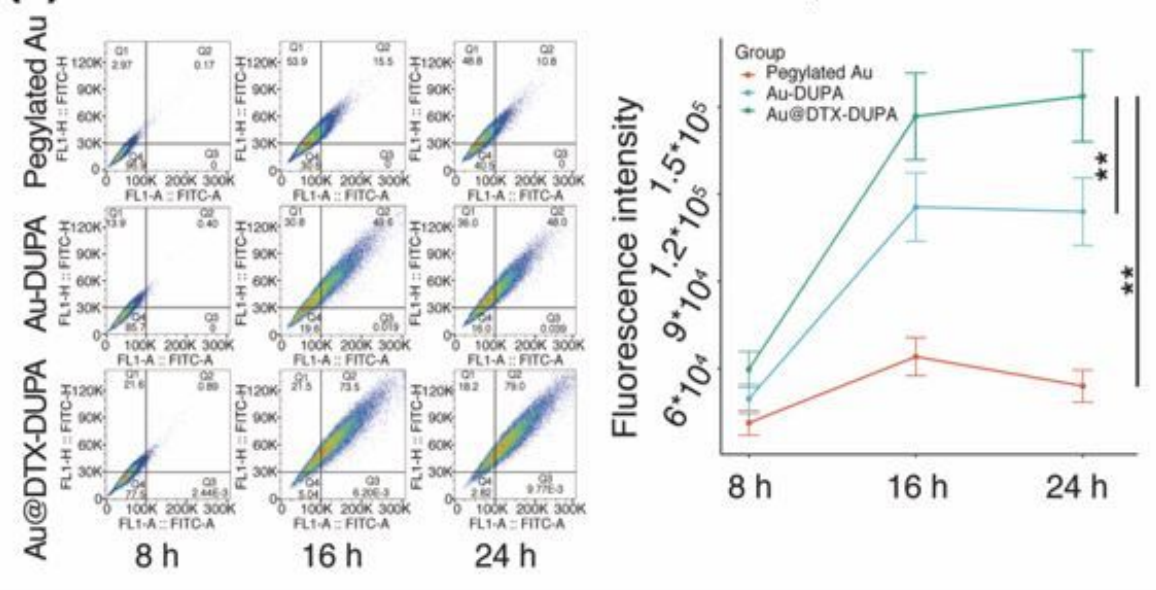

\section{Figure 3}

(a) Cleavage PARP of 22RV1 cells under various treatments. B-actin served as loading control (IR dose = 4Gy). (b) Colony formation of 22RV1 cells received IR only, Pegylated Au + IR, Au-DUPA NPs + IR, and Au@DTX-DUPA NPs + IR. (c) Survival fraction of 22RV1 cells incubated with various NPs and received gradient radiation dose of $0,2,4$, and 6 Gy IR. Data were represented as mean $\pm S D(n=5)$. (d) DNA content and cell cycle distribution of 22RV1 cells incubated with Au-DUPA NPs, free DTX, or Au@DTX DUPA NPs for different incubated periods. (e) Quantitative analyzed the concentration of Pegylated $\mathrm{Au}$ NPs, Au-DUPA NPs, or Au@DTX -DUPA NPs in 22RV1 cells for different incubated periods. Data were represented as mean $\pm S D(n=5)$. $P$ values were calculated using the two-tailed unpaired Student's t-test. $\star P<0.05, * * P<0.01$. 
(a)

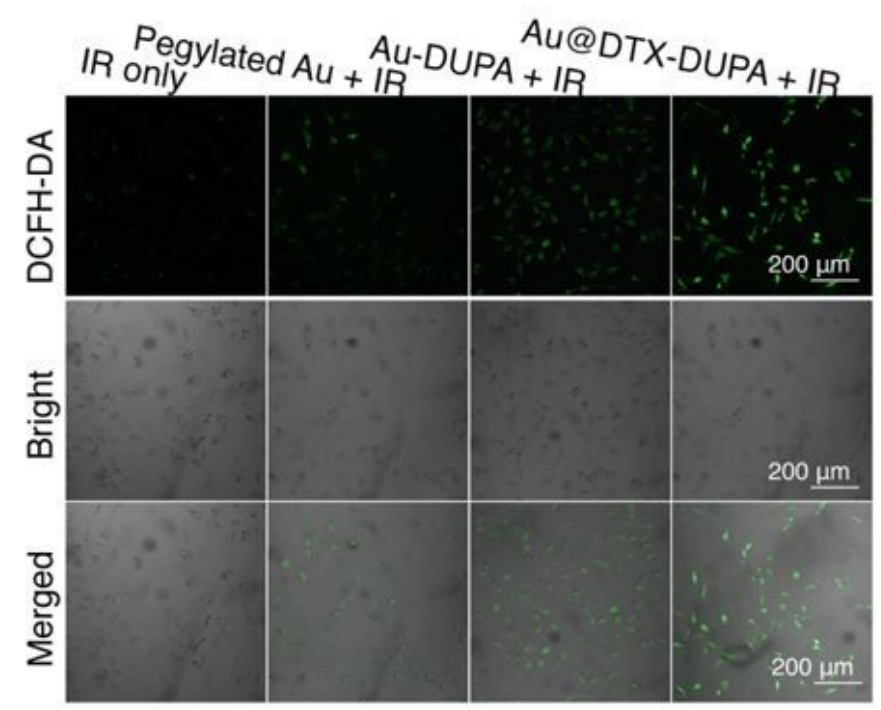

(c)

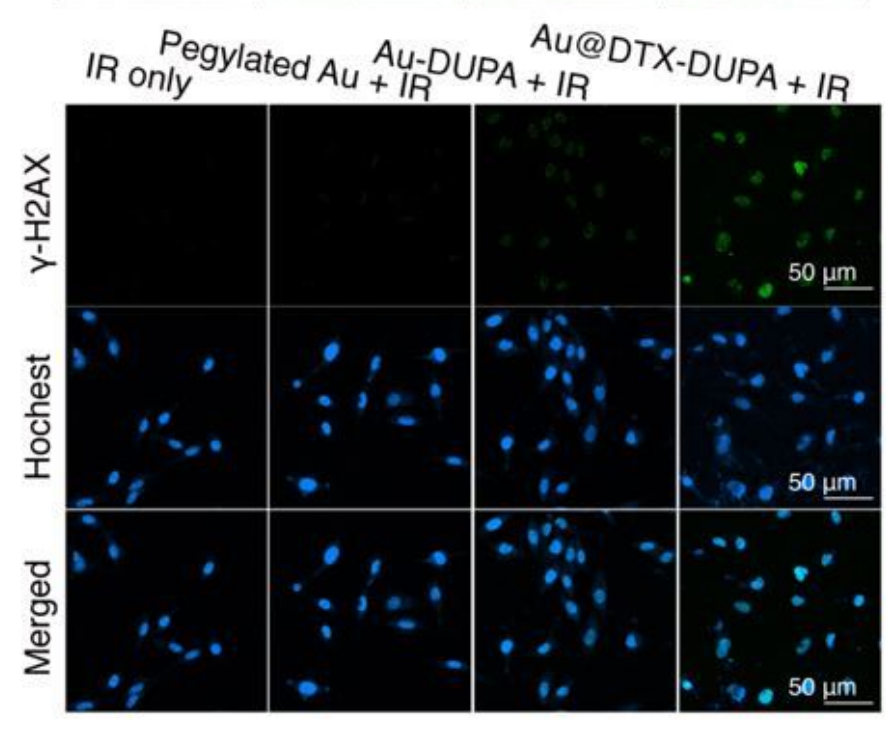

(b)

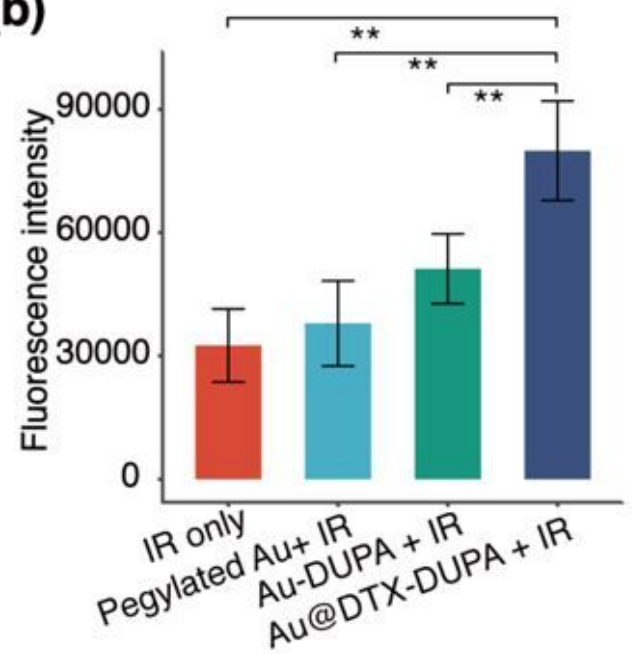

(d)

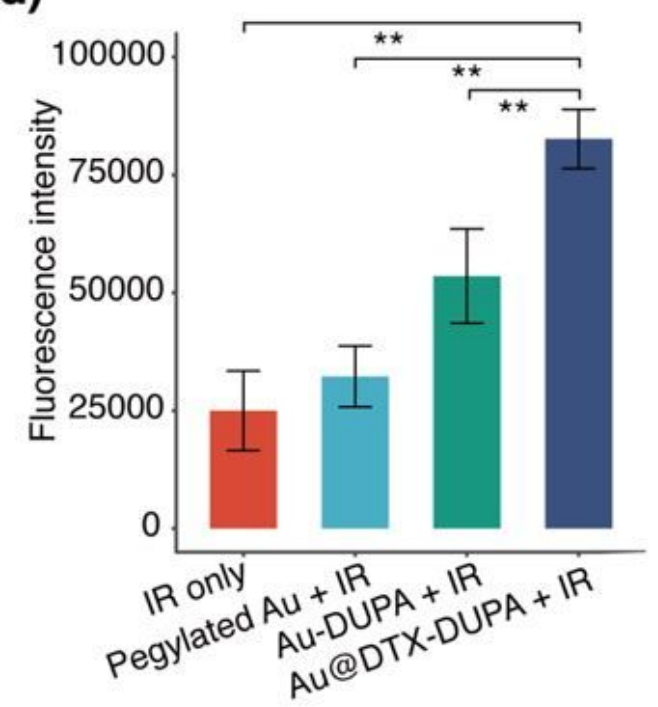

\section{Figure 4}

(a) Confocal fluorescence images of ROS marked by DCFH-DA in 22RV1 cells treated with IR only, Pegylated Au NPs + IR, Au-DUPA NPs + IR, and Au@DTX-DUPA NPs + IR. The IR dose was 4 Gy. (b) Quantitative the ROS in 22RV1 cells received different treatments with FACS. Data were represented as mean $\pm S D(n=5)$. (c) Confocal fluorescence images of DSBs marked by $Y-H 2 A X$ in 22RV1 cells treated with IR only, Pegylated Au NPs + IR, Au-DUPA NPs + IR, and Au@DTX-DUPA NPs + IR. The IR dose was 4 Gy. (d) Quantitative the DSBs in 22RV1 cells received different treatments with FACS. Data were represented as mean $\pm S D(n=5)$. P values were calculated using the two-tailed unpaired Student's t-test. ** $\mathrm{P}<0.01$. 
(a)

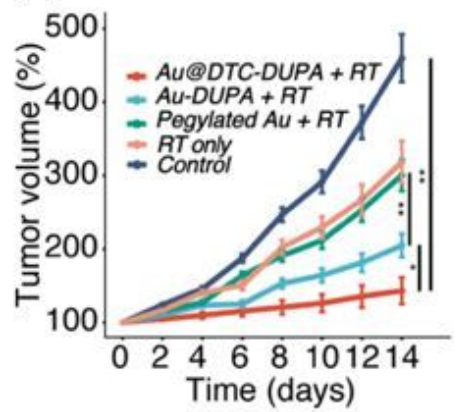

(b)

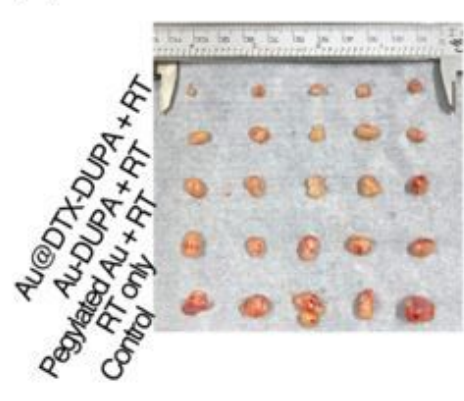

(c)

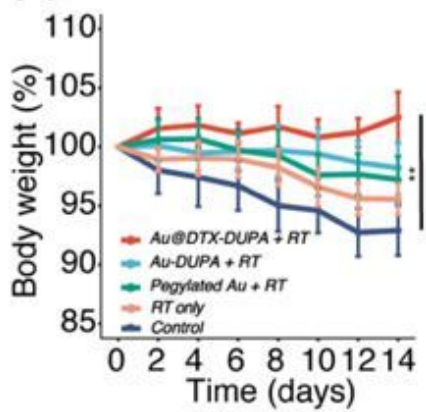

(d)

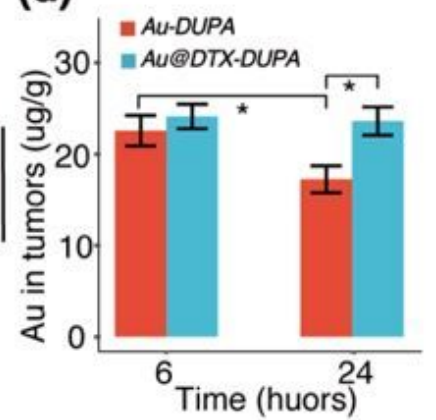

(e)

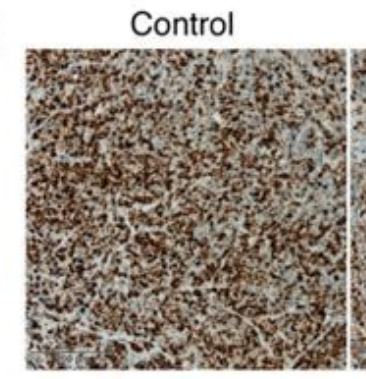

RT only

Pegylated $\mathrm{Au}+\mathrm{RT}$

Au-DUPA + RT

Au@DTX-DUPA + RT
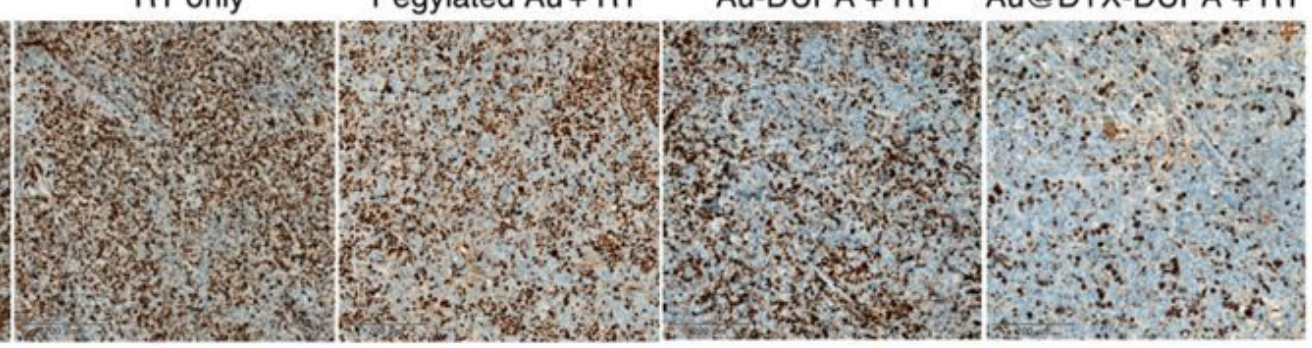

Figure 5

(a) Tumor growth curves of 22RV1 cell xenograft tumor bearing nude mice in different groups after various treatments. The irradiation dose of electron beam was $6 \mathrm{~Gy}$. Tumor volumes have been normalized according to their initial sizes. Data were represented as mean $\pm S D(n=5)$. (b) Weight change curves of mice in different groups after various treatments. Mice weight had been normalized according to their initial weight. Data were presented as mean \pm SD $(n=5)$. (c) Images of harvested tumors of different groups after various treatments on 15th days after treatments. (d) Ki67 staining of tumor slices collected from different groups 15 days after receiving different treatments. (e) Au concentration in 22RV1 xenograft tumors at 6 and 24h after injection of Au-DUPA NPs or Au@DTX-DUPA NPs. Data were represented as mean $\pm S D(n=5)$. P values were calculated using the two-tailed unpaired Student's t-test. ${ }^{\star} p<0.05,{ }^{\star \star} p<0.01$.

\section{Supplementary Files}

This is a list of supplementary files associated with this preprint. Click to download.

- Scheme1.jpg

- SupportingInformationJON.docx 